\title{
Researching Race in Computer Science Education: Demystifying Key Vocabulary and Methods
}

\author{
Colleen M. Lewis (Moderator) \\ Computer Science Dept. \\ Harvey Mudd College \\ Claremont, CA, USA \\ lewis@cs.hmc.edu
}

\author{
Joanna Goode \\ Department of Education Studies \\ University of Oregon \\ Eugene, OR, USA \\ goodej@uoregon.edu
}

\author{
Allison Scott \\ Chief Research Officer \\ Kapor Center \\ Oakland, CA, USA \\ allison@kaporcenter.org
}

\author{
Niral Shah \\ College of Education \\ University of Washington \\ Seattle, WA, USA \\ niral@uw.edu
}

\author{
Sepehr Vakil \\ School of Education and Social Policy \\ Northwestern University \\ Evanston, IL, USA \\ sepehr.vakil@gmail.com
}

\begin{abstract}
Diversity and inclusion are popular topics at SIGCSE. However, few researchers examine questions specifically focused on race. Such research is of great interest to the SIGCSE community, but is typically conducted by education faculty and published in education journals. This panel attempts to introduce attendees to relevant background and methods, such that attendees can more easily understand and contribute to computer science education research related to race. This panel attempts to bridge our two communities by inviting race scholars from education to share their expertise with computer science education researchers and practitioners.
\end{abstract}

\section{KEYWORDS}

race; equity; diversity; critical race theory; intersectionality

\section{ACM Reference Format:}

Colleen M. Lewis (Moderator), Joanna Goode, Allison Scott, Niral Shah, and Sepehr Vakil. 2020. Researching Race in Computer Science Education: Demystifying Key Vocabulary and Methods. In Proceedings of SIGCSE '20: Special Interest Group for Computer Science Education (SIGCSE '20). ACM, New York, NY, USA, 2 pages. https://doi.org/10.1145/1122445.1122456

\section{SUMMARY}

At ICER in 2019, Kafai, Proctor, and Liu highlighted the dearth of computer science (CS) education research taking a critical approach [5], which they characterize as prioritizing "Justice, critical understanding, [and] enacting social change." The goal of the panel is to inspire and empower SIGCSE attendees to adopt a critical approach and address issues of race in CS education. There is a steep learning curve for understanding and contributing to CS education research

Permission to make digital or hard copies of part or all of this work for personal or classroom use is granted without fee provided that copies are not made or distributed for profit or commercial advantage and that copies bear this notice and the full citation on the first page. Copyrights for third-party components of this work must be honored. For all other uses, contact the Owner/Author.

SIGCSE '20, March 11-14, 2020, Portland, OR, USA

(C) 2020 Copyright is held by the owner/author(s).

ACM ISBN 978-1-4503-6793-6/20/03.

https://doi.org/10.1145/3328778.3366965 related to race. The panelists are committed to make this important work accessible to SIGCSE attendees. The primary audience is SIGCSE attendees interested in learning more about education research that studies race. The secondary audience is researchers who are interested in contributing to this research agenda.

\section{PANEL STRUCTURE}

- Introductions: 5 minutes. The moderator will begin by introducing each of the panelists.

- Vocabulary: 15 minutes. Each panelist will introduce three to four terms that are important background for researching race. Slides will be posted online and each term will include links for additional information. Additionally, the moderator will prompt the panelists to define the terms they are using to make the panel content as accessible to novices as possible.

- Q\&A: 15 minutes. Panelists will define additional terms as requested by SIGCSE attendees in person or over Twitter.

- Research Briefs: 20 minutes. Each panelist will introduce a race-focused research question they have explored and introduce the methods, findings, and relevance of this work.

- Closing Q\&A: 20 minutes. Panelists will continue to address questions and concerns from SIGCSE attendees.

\section{POSITION STATEMENTS}

The inclusion of these four experts is important for showing how a breadth of research methods apply to researching race within CS.

\subsection{Joanna Goode - Policies \& Practices}

Joanna Goode is a Professor in the College of Education at the University of Oregon. She began her career in education as a high school CS teacher in a large, diverse urban school, and she builds on this experience to research how educational policies and practices can foster equity, access, and inclusion in K-12 CS education $[3,4,7,8]$. Joanna's research focuses on how teachers talk, learn, and enact race-conscious and gender-conscious approaches in professional learning spaces and in school classrooms. Joanna's recent work examines how teacher education settings can serve as sites to intentionally disrupt colorblind discourse in CS policy and practice. 
Joanna leads multiple NSF research projects that support this research. She co-developed the equity-focused Exploring Computer Science high school course, and is the co-author of the book, Stuck in the Shallow End: Education, Race, and Computing [7].

\subsection{Allison Scott - Participation \& Retention}

Dr. Allison Scott is the Chief Research Officer for the Kapor Center, where she leads a research agenda which examines equity in CS education, participation and retention in the technology workforce among underrepresented populations, and intersectionality and barriers facing women of color in computing [1, 10-13]. This agenda informs the design and implementation of strategies, policies, and practices to diversify the technology and entrepreneurship ecosystem, to improve opportunities for underrepresented communities and strengthen our nation's global competitiveness. Dr. Scott is currently Principal Investigator for a 3-year NSF grant analyzing CS equity in California; and Co-PI for the Women of Color in Computing Collaborative to increase participation of women of color across the computing pipeline. Previous positions include: Program Leader for the National Institutes of Health's Enhancing the Diversity of the Biomedical Workforce Initiatve; Director of Research and Evaluation for the Level Playing Field Institute, and Data Analyst for the Education Trust-West. Dr. Scott holds a Ph.D. in Education from the University of California, Berkeley and a B.A. in Psychology from Hampton University.

\subsection{Niral Shah - Racial Narratives and Learning}

Niral Shah is an Assistant Professor in the College of Education at the University of Washington. His research focuses on racial equity in STEM education [2, 6, 9, 14-16]. Dr. Shah's work has looked at how racial narratives about STEM ability affect students' identities and participation in classrooms. For example, he has shown how the false "Asians are good at math" narrative dehumanizes Asian people, and also links to other racist narratives that position non-Asian students of color as intellectually inferior. He is also co-developer of the EQUIP classroom observation tool (https://www.equip.ninja/), which teachers and district leaders are using to identify and attenuate implicit bias in classrooms. Dr. Shah is a National Academy of Education/Spencer Dissertation Fellow and Postdoctoral Fellow, and his work has been funded by the National Science Foundation, Institute of Education Sciences, and the Spencer Foundation.

\subsection{Sepehr Vakil - Learning \& Identity}

Sepehr Vakil is an assistant professor of Learning Sciences in the School of Education and Social Policy at Northwestern University. Previously he was Assistant Professor of STEM Education and the Associate Director of Equity \& Inclusion in the Center for STEM Education at the University of Texas at Austin. Broadly his research examines the intersections of learning, identity, race, power, and ethics in secondary and post-secondary engineering and CS contexts [17-19]. Dr. Vakil's teaching and research are informed by sociocultural theories of learning, practice, and pedagogy. He recently received the National Science Foundation's early CAREER award, as well as the National Academy of Education/Spencer Foundation Postdoctoral fellowship. He received his $\mathrm{PhD}$ in the Education in
Mathematics, Science, and Technology program at UC Berkeley, and his B.S and M.S in Electrical Engineering from UCLA.

\section{ACKNOWLEDGMENTS}

This material is based upon work supported by the National Science Foundation under Grant numbers CNS-1743195, CNS-1339404, EHR-1821136.

\section{REFERENCES}

[1] Kapor Center, ASU Center for Gender Equity in Science, and Technology. 2018, August. Data Brief: Women and Girls of Color in Computing. Technical Report. https://www.wocincomputing.org/wp-content/uploads/2018/08/ WOCinComputingDataBrief.pdf

[2] Sally A Fincher and Anthony V Robins. 2019. The Cambridge Handbook of Computing Education Research. Cambridge University Press, New York, NY.

[3] Joanna Goode, Stephany Runninghawk Johnson, and Krystal Sundstrom. 2018. Disrupting colorblind teacher education in computer science. Professional Development in Education (2018), 1-14.

[4] Joanna Goode and Jean J. Ryoo. 2019. Teacher Knowledge for Inclusive Computing Learning. Cambridge University Press, New York, NY, 709âĂŞ726. https://doi. org/10.1017/9781108654555.025

[5] Yasmin Kafai, Chris Proctor, and Debora Lui. 2019. From Theory Bias to Theory Dialogue: Embracing Cognitive, Situated, and Critical Framings of Computational Thinking in K-12 CS Education. In Proceedings of the 2019 ACM Conference on International Computing Education Research (ICER '19). ACM, New York, NY, USA, 101-109. https://doi.org/10.1145/3291279.3339400

[6] Colleen M. Lewis, Niral Shah, and Katrina Falkner. 2019. Equity and diversity. In The Cambridge Handbook of Computing Education Research, Sally A. Fincher and Anthony V. Robins (Eds.). Cambridge University Press, Cambridge, Chapter 16, 481-510.

[7] Jane Margolis. 2010. Stuck in the shallow end: Education, race, and computing. MIT Press, Cambridge, MA.

[8] J. Nakajima, T.M \& Goode. 2019. Teachers' Approaches to Mak(e)ing Computing Culturally Responsive: Electronic-Textiles in Exploring Computer Science Classes. (2019).

[9] Daniel L Reinholz and Niral Shah. 2018. Equity analytics: A methodological approach for quantifying participation patterns in mathematics classroom discourse. fournal for Research in Mathematics Education 49, 2 (2018), 140-177.

[10] Allison Scott, Freada Kapor Klein, Frieda McAlear, Alexis Martin, and Sonia Koshy. 2018, February 2. The Leaky Tech Pipeline: A Comprehensive Framework for Understanding and Addressing the Lack of Diversity across the Technology Ecosystem. Technical Report. https://mk0kaporcenter5ld71a.kinstacdn.com/ wp-content/uploads/2018/02/KC18001_report_v6-1.pdf

[11] Allison Scott, Freada Kapor Klein, and Uriridiakoghene Onovakpuri. 2017, April 27. Tech Leavers Study: A First-of-its-Kind Analysis of Why People Voluntarily Left Tech fobs. Technical Report. https://mk0kaporcenter5ld71a.kinstacdn.com/ wp-content/uploads/2017/08/TechLeavers2017.pdf

[12] Allison Scott, Sonia Koshy, Meghana Rao, Laura Hinton, Julie Flapan, Alexis Martin, and Frieda McAlear. 2019, June 17. Computer Science in California's Schools: An Analysis of Access, Enrollment \& Equity. Technical Report. http: //tinyurl.com/CSinCAschools

[13] Allison Scott, Alexis Martin, Frieda McAlear, and Sonia Koshy. 2017. Broadening participation in computing: examining experiences of girls of color. In Proceedings of the 2017 ACM Conference on Innovation and Technology in Computer Science Education. ACM, 252-256.

[14] Niral Shah. 2017. Race, Ideology, and Academic Ability: A Relational Analysis of Racial Narratives in Mathematics. Teachers College Record 119, 7 (2017), 1-42.

[15] Niral Shah and Zeus Leonardo. 2016. Learning discourses of race and mathematics in classroom interaction: A poststructural perspective. In Power and privilege in the learning sciences, Indigo Esmonde and Angela N Booker (Eds.). Routledge, New York, NY, 50-59.

[16] Niral Shah and Colleen M Lewis. 2019. Amplifying and attenuating inequity in collaborative learning: Toward an analytical framework. Cognition and Instruction (2019), 1-30.

[17] Sepehr Vakil. 2018. Ethics, identity, and political vision: Toward a justice-centered approach to equity in computer science education. Harvard Educational Review 88,1 (2018), 26-52.

[18] Sepehr Vakil and Maxine McKinney de Royston. 2019. Exploring Politicized Trust in a Racially Diverse Computer Science Classroom. Race Ethnicity and Education 22, 4 (2019), 545-567.

[19] Sepehr Vakil and Jennifer Higgs. 2019. It's About Power. Commun. ACM 62, 3 (Feb. 2019), 31-33. https://doi.org/10.1145/3306617 